\title{
An empirical study on adult students' English mobile learning based on frame model
}

\author{
Zhihua Shen ${ }^{1}$ \\ ${ }^{1}$ Handan Radio and TV University, Hebei, China, 056004
}

\begin{abstract}
Based on the framework for the rational analysis of mobile education (frame), this study takes 60 adult non English majors from Handan radio and TV University as the research objects, and uses tablet computers or smart phones as mobile devices to conduct the pre-test and post test, Questionnaire and interview were carried out from the aspects of experimental effect and learner satisfaction. The collected data were analyzed by spss 24.0 software to track the relationship among society, equipment and learners reflected by the data.
\end{abstract}

\section{Raising of the problem}

In this era of knowledge and information explosion, with the rapid development of mobile computing technology and communication technology, a new learning mode, mobile learning, has gradually become a hot spot in the field of education due to its advantages of flexibility of learning scene, personalization of learning content, portability of learning equipment, fragmentation of learning time, etc. Fang haiguang et al. (2011) believe that in the next 20 years, the development of mobile learning in China will go through three stages: the construction of basic environment, the construction of knowledge system and the construction of learning service. The transition between each stage is an iterative cycle. The problems and challenges faced by domestic mobile learning research are: from "technology" to "learning", the research focus changes, through application and practice research, to implement the effect of mobile learning (Wang, et al., 2013). Among all subjects, mobile learning is more suitable for English and other language subjects (Huseyin, 2014). In recent years, in many studies of English mobile learning, researchers mostly focus on the effectiveness of mobile learning for primary school students, middle school students or full-time college students, and basically reach a consensus. However, there are relatively few studies on adult students' English learning, and lack of deep experience and understanding of the positive role of mobile learning. In view of this, this study will carry out an empirical study of mobile learning among 60 adult students in RTVU, aiming to promote the effective learning of adult students, provide ideas and reference, and enrich and expand the research of mobile learning.

\section{A survey of mobile learning}

\section{(1) Foreign related research}

Foreign research on mobile learning has sprung up in the United States. In 1994, Carnegie Mellon University proposed to carry out wireless Andrew project (Wu W-H, et al., 2012) in order to change the traditional way of learning, eager to make learners full of passion and vitality in the learning process. Among them, North America, Europe and the United Kingdom are the main research sites. The main purpose of this research is to change the traditional teaching mode, so that students can enjoy the convenience of mobile learning supported by wireless communication technology in the campus environment, and create a precedent for mobile learning research. The first one to combine mobile learning with foreign language learning is the research led by Stanford Learning Laboratory (Shen Xuan, 2016), and then some countries and companies such as Japan, BBC, Australia have also made bold attempts in this area. The results show that mobile learning can stimulate learners' passion for foreign language learning and improve learning efficiency. In order to keep abreast of the latest developments of English mobile learning research abroad, the project team searched the EBSCO database for literature in the past five years, with the key fields of "mobile learning" and "English learning"; The search time was limited from January 1, 2015 to December 31, 2019, and 64 valid articles were obtained. Then all the search results were statistically analyzed: 


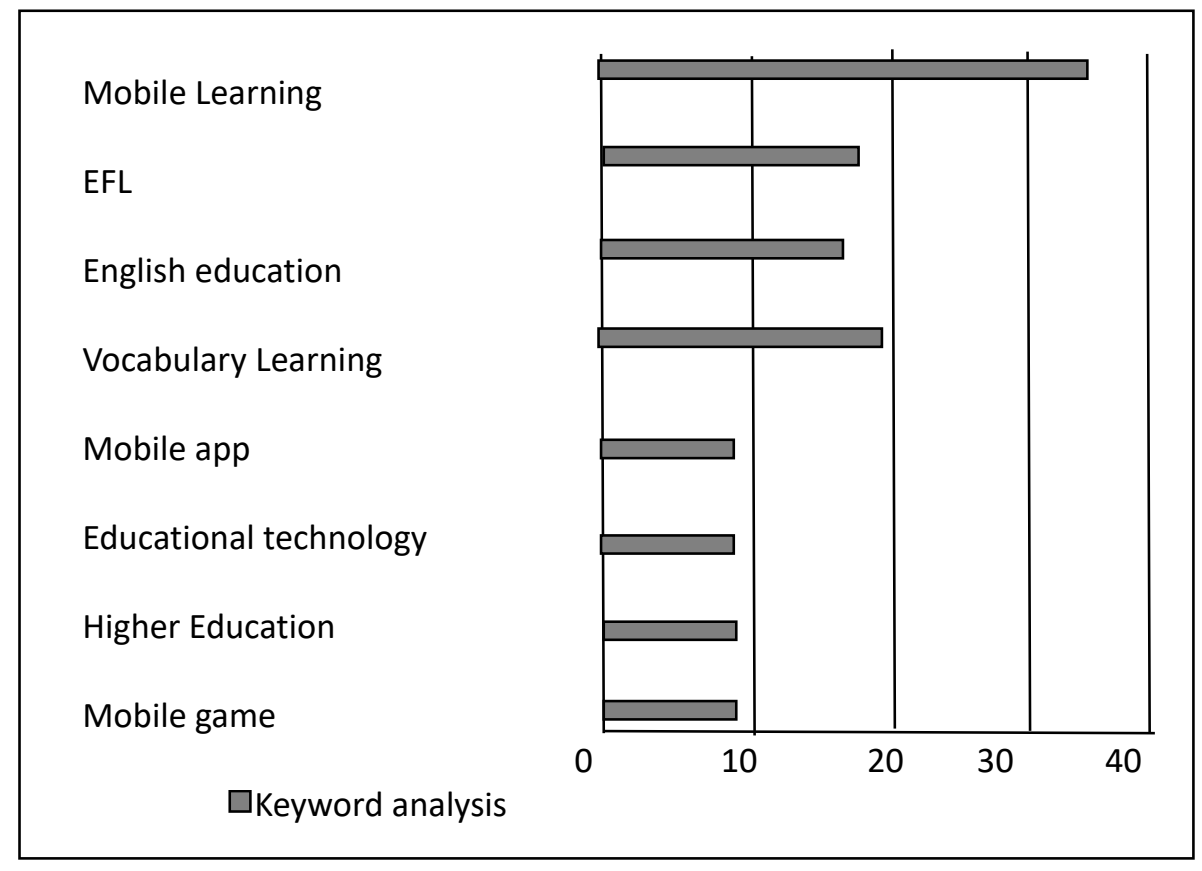

Figure1 column chart of keyword distribution in foreign research

\section{(2) Domestic related research}

At present, the domestic research on "mobile learning" has accumulated a lot of achievements. According to the literature, the research of mobile learning in China began in 2000 with Desmond, a famous international distance education expert ' Dr. Keegan (2000) made an academic report entitled "distance learning digital learning mobile learning" on the 40th anniversary of Shanghai TV University. He proposed that "mobile learning is the future of learning" and introduced the concept of mobile learning into China. Since then, Chinese experts and scholars began to pay attention to mobile learning, And related research and practice are carried out in succession. Among them, the mobile learning project in 2001, sponsored by the Higher Education Department of the Ministry of education and undertaken by Peking University, created a precedent of mobile learning research in China. In 2003, Chinese education expert GUI Qingyang published "m-learning: the future of foreign language learning in China" in "foreign language audio-visual teaching", which represents the beginning of the research on the combination of mobile learning and foreign language learning in China. He pointed out that "the impact of M-learning on foreign language learning and foreign language teaching in China is immeasurable. This is a new learning revolution and the future of foreign language learning in China. " ( Guiqingyang, 2003)

\section{Theoretical analysis}

\section{(1) Frame model}

Koole's frame model of Athabasca University has been widely cited and applied in educational research literature for more than ten years, which also provides a solid theoretical basis for this study.

The frame model was developed for master's thesis by koole when mobile learning first entered the mainstream of education research in 2004. At that time, there were almost no other mobile learning models and frameworks available. The master's thesis was published online in 2006 , which may contribute to the promotion of the model in the world. At first, koole mainly used Constructivism Perspective, but also used cognitive theory for reference, especially focused on situational learning, human-computer interaction and distance education. Since then, koole turned to the frame model of social materialism, using an ontological point of view, that human and material are equally important. The frame model describes three levels of influencing and co generating mobile learning through Venn diagram: device aspect, learner aspect and social aspect.

(2) Analysis of frame elements

1. Equipment level (d)

Each student in the experimental group is equipped with the National Open University Learning School (PAD) purchased by the University, and the open cloud academy app is installed on the pad. The pad has strong social media function, and can be downloaded and installed with wechat, QQ and other social media software. In the open cloud academy, there are the learning contents of humanistic English 3 and humanistic English 4 with complete digital learning resources, including listening, speaking, reading, writing and other materials. Students can use pad for online learning, or download learning resources to pad in advance for offline mobile learning. Students can also use smart phones to download the open cloud academy app for online or offline mobile learning. You can also use mobile phones, pads, laptops or desktop computers to $\log$ on to the National Open University learning network. After entering the student space, you can choose courses for online mobile learning network core courses. There are many choices for students, one of which is suitable for them. 


\section{Learner level (L)}

There are 30 students in the experimental group, 15 male and 15 female in half, 6 under 25 years old, 21 between 26 and 35 years old, and 3 between 36 and 45 years old. The proportion of young people is larger, and $90 \%$ of the learners under 35 years old. These students are easy to accept new things, are very keen on new devices such as smart phones and pad, and have a high level of technology. They have a strong ability to use the network to obtain resources or information, and can skillfully use social media communication software such as wechat and QQ. This feature creates conditions for the development of mobile learning (Liu Yongquan et al., 2012). In addition, these adult students can voluntarily participate in the pilot project and sign a letter of commitment, which shows that they have a desire to learn and a positive attitude, which is also the premise of the emergence and continuation of effective activities. However, due to work or family reasons, there is often no fixed large amount of time. Mobile English learning can just meet the needs of adult students who use their spare time to carry out fragmented learning anytime and anywhere.

\section{Social dimension (s)}

At the social level, the factors of social interaction and learning cooperation need to be considered, and the rules of cooperation are determined by the learners' cultural background or their interaction (Li Yuan, 2019). The social aspect of this study mainly refers to the social learning activities of the curriculum, including group cooperative learning activities and large-scale group learning demonstration activities. The students in the experimental group are divided into six groups to complete the group discussion, arrangement, summary, report, display and other learning tasks, which can let each student express their opinions and ideas, stimulate the thought collision between students, and provide students with the opportunity to communicate with many people to learn English.

\section{Empirical analysis}

\section{Teaching materials}

This study uses the newly developed public English multimedia series "humanities English 3" and "humanities English 4" of National Open University, including four parts of teaching materials: listening, speaking, reading and writing. The two-dimensional code is attached to the listening and reading materials in the book. Students can scan the two-dimensional code on their mobile phones and get the standard speech materials read by British and American people. They can also scan the two-dimensional code behind the book and $\log$ in to open cloud academy for mobile learning.

\section{Electronic equipment}

In addition to using smart phones, the school also provides each student in the experimental group with pad, which is installed with learning resources of humanistic English 3 and humanistic English 4, for free, providing more choices and convenience for students.

3. National Open University Learning Network

Online high-quality digital learning resources for adult learners are rich, which support learners to access students' personal space through computers and various mobile terminals, and then select the courses to carry out online mobile learning English network core courses.

4. Pre and post test paper

In this study, before and after the teaching intervention, the students were tested before and after the teaching intervention. The test adopted the relatively mature standardized test paper, which was used by five pilot companies in the National Radio and TV university system. The test questions are divided into two parts. One is the oral test question for oral communication, which has 40 points; The second is to investigate the basic knowledge of language written test questions 60 points, two parts of the test questions a total of 100 points. However, in order to avoid the chance of achievement, we also did a pre research before the experiment, and invited three students to do these questions, which ensured the reliability and validity of the test paper.

\section{Final test paper}

In order to avoid the pretest effect, this study also uses the National Public English test paper organized by the National Open University headquarters to supplement and verify. At this time, the volume can be used at a unified time in the National Radio and TV university system, which can exclude the influence of irrelevant variables to a certain extent.

6. Questionnaire and interview

At the end of the first semester of the pilot project, a questionnaire was designed and created to investigate the recognition, support and satisfaction of the new and old learning styles. All the questions were scored with Likert's five point scale. In addition, five students were invited to the school to participate in the interview activities, to conduct in-depth investigation on some specific questions and to supplement the questions that are inconvenient to be investigated by the questionnaire.

\section{Results and discussion}

At the end of the semester, this paper first analyzes the students' academic performance, and then designs a questionnaire to investigate the effect of mobile learning from the perspective of participants' learning experience to verify its effectiveness.

(1) Pretest results

Table 1 pretest comparison of the two groups receiving different experimental treatments

\begin{tabular}{|c|c|c|c|c|c|}
\hline & group & Number of cases & average value & standard deviation & Mean standard error \\
\hline \multirow{2}{*}{ before } & experience group & 30 & 49.47 & 10.928 & 1.995 \\
\cline { 2 - 6 } & control group & 30 & 48.20 & 9.561 & 1.746 \\
\hline
\end{tabular}




\section{(2) Post test results}

Table 2 post test results of two groups treated with different experiments

\begin{tabular}{|c|c|c|c|c|c|}
\hline & group & Number of cases & average value & standard deviation & Mean standard error \\
\hline \multirow{2}{*}{ before } & experience group & 30 & 66.93 & 10.812 & 1.974 \\
\cline { 2 - 6 } & control group & 30 & 50.30 & 10.971 & 2.003 \\
\hline
\end{tabular}

Table 3 post test independent sample t-test of two groups receiving different experimental treatments

\begin{tabular}{|c|c|c|c|c|c|c|c|}
\hline & & \multicolumn{2}{|c|}{$\begin{array}{c}\text { Raven's test of variance } \\
\text { equivalence } \\
\text { T test for mean equivalence }\end{array}$} & \multicolumn{4}{|c|}{$\begin{array}{c}\text { Raven's test of variance equivalence } \\
\text { T test for mean equivalence }\end{array}$} \\
\hline \multirow{2}{*}{ after } & $\mathrm{F}$ & Significance & $\mathrm{t}$ & freedom & $\begin{array}{c}\text { Significance } \\
\text { (two tailed) }\end{array}$ & Mean difference \\
& $\begin{array}{c}\text { Assumed } \\
\text { equivariance }\end{array}$ & .039 & .845 & 4.973 & 58 & .000 & 13.733 \\
\cline { 2 - 8 } & $\begin{array}{c}\text { Equivariance } \\
\text { is not assumed }\end{array}$ & & & 4.973 & 57.972 & .000 & 13.733 \\
\hline
\end{tabular}

One week after the end of the experiment, the two groups were tested, and the results were tested by independent sample t-test. Table 2 shows that the scores of the experimental group have changed significantly after receiving the mobile learning teaching intervention, with an average of 66.93 , which is significantly higher than that of the control group of 50.30. According to table $3, \mathrm{t}(58)=4.973, \mathrm{P}<0.001$, which shows that there is a significant difference between the two groups in post test results, and it also proves that there is a significant difference in learning forms between the two groups to a certain extent.

\section{Conclusion}

Guided by modern education theories at home and abroad, and based on the rational analysis framework of mobile learning, this study innovates teaching programs, constructs the teaching design mode of mobile learning, uses social media QQ group and wechat group to supplement learning support services, and uses mobile learning to meet the flexible learning needs of adult students and solve their learning difficulties, In order to improve the English learning effect of adult students, spss 24.0 is used to mine and analyze the data of the learning results, and the effect of the implementation of the project is verified and compared. The research shows that the use of frame theory model, through the promotion of mobile learning intervention, can help students improve the learning effect, and can effectively improve the English learning status of adult students.

\section{Fund Project:}

National Open University's 2018 annual planning key project "comparative study on English learning effect under mobile learning mode and traditional learning mode" (project number: g18a0131z); Key projects of national education information technology research in 2018: Practical Research on the reform of mobile learning mode based on online courses (No.: 186120011);
Handan education science research "13th five year plan" key topic: online teaching practice research based on English open mode (No.: 20zd010)

\section{References}

1. Cui guangzuo, Li Shufang, sun zuihua, et al. 2002. Mobile Education -- a new direction of modern educational technology $[\mathrm{J}]$. Educational technology communication (1): 08

2. Chen Yiqin. 2013. Survey and Research on adult learners' mobile learning [J]. China's Distance Education (10): 47-52

3. CENS. 2016. Application of mobile learning mode in English Open Education [J]. English Square, 2016 (10): $86-87$

4. Desmond ' Ji Geng, Xu HuiFu. 2004. Mobile Learning: learning for the next generation: a theme report at the 18th annual meeting of the association of Asian Open Universities [J]. Open education research, (6) 22-27

5. Desmond ' Ji Geng. 2013. Mobile learning today [J]. Journal of Beijing Radio and Television University (6): 5-9

6. Fang haiguang, Wang Hongyun, Huang Ronghuai. 2011. System environment roadmap of mobile learning -- review of mobile learning research and application case studies at home and abroad [J]. Modern educational technology 21 (01): 14-20 